\title{
AVALIAÇÃO DOS EFEITOS DA IMPERMEABILIZAÇÃO DO SOLO URBANO NA ALTA BACIA DO CÓRREGO CASCAVEL - GOIÂNIA /GO
}

\author{
Amanda Sanches Machado ${ }^{(a)}$, Helio Junio Moreira De Paula ${ }^{(a)}$, Hellbia Samara Moreira de
} Carvalho Rodrigues ${ }^{(b)}$, Karla Maria Silva de Faria ${ }^{(\mathbf{c})}$.

(a) Bacharel em Ciências Ambientais, Instituto de Estudos Sócio Ambientais/IESA, Universidade Federal de Goiás/UFG. amanda.sanchesmachado@hotmail.com; junio.moreira.depaula@gmail.com

(b) Doutoranda em Geografia, Instituto de Estudos Sócio Ambientais/IESA, Universidade Federal de Goiás/UFG. hellbiageografia1@gmail.com

(d) Instituto de Estudos Sócio Ambientais/IESA, Universidade Federal de Goiás/UFG. karla faria@ ufg.com

\section{EIXO: BACIAS HIDROGRÁFICAS E RECURSOS HÍDRICOS: ANÁLISE, PLANEJAMENTO E GESTÃO}

\begin{abstract}
Resumo
O processo de ocupação da bacia do córrego Cascavel, situada na porção sul do município de Goiânia é antigo e foi em 2009 potencializado pela adequação de uma área verde à categoria de unidade de conservação, que atraiu o ramo imobiliário e um rápido processo de verticalização da região das nascentes desta bacia. $\mathrm{O}$ objetivo do trabalho foi o de avaliar o aumento da impermeabilização nessa região a fim de correlacionar com os impactos identificados na unidade de conservação. Os procedimentos metodológicos envolveram a elaboração de mapas de uso de solo para o ano de $2002 \mathrm{e}$ 2012, visitas em campo e discussão teórica sobre a temática. Os resultados para o recorte temporal indicam aumento das áreas impermeabilizadas, dos processos erosivos lineares e fluviais, assoreamento do canal de drenagem; aumento de áreas de inundação e alagamento o que compromete a qualidade ambiental da unidade de conservação.
\end{abstract}

Palavras chave: Urbanização, Inundação, Verticalização, Parque Cascavel, Impactos ambientais.

\section{Introdução}

A cidade de Goiânia, capital do Estado de Goiás, reflete os problemas urbanos da modernidade. Planejada na década de 1930 para 50.000 habitantes, hoje se configura como uma metrópole com cerca de 1.300.000 habitantes (IBGE, 2010), que apresenta vários problemas urbanos e ambientais decorrentes do crescimento acelerado e mal planejado da cidade. E, um dos problemas que vem chamando a atenção da mídia e da população são os processos erosivos, as inundações e alagamentos.

O fenômeno de inundações e alagamentos tem afetado a vida da população goianiense, implicando em prejuízos materiais, sociais e perdas de vida humana. É comum entre os meios de comunicação, ser noticiado vítimas de inundações ou alagamentos que perderam bens materiais, mortes e ferimentos graves. Em médio e longo prazo há diminuição da qualidade de vida da população residente na capital de Goiás tanto em áreas consideradas como nobres, como nas regiões periféricas. 


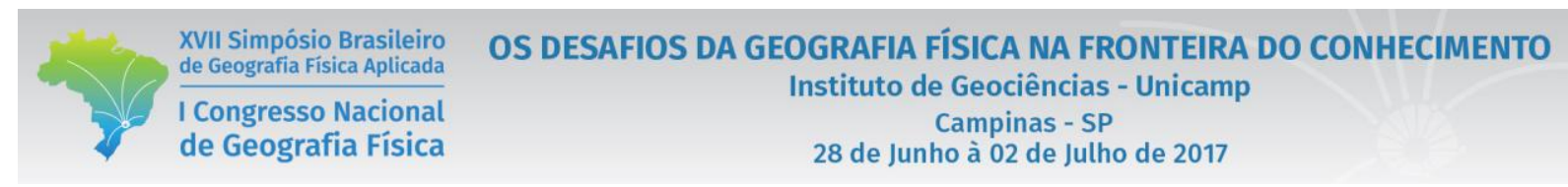

Para minimizar os impactos em áreas urbanas originados pela impermeabilização excessiva são propostas pela engenharia alternativas de contenção dos escoamentos superficiais, que permitem uma maior infiltração e a percolação da água no sistema de drenagem urbana e que podem ser adotados nas unidades individuais assim como a criação de reservatórios ou bacias para armazenamento temporário da água escoada nas proximidades (CANHOLI, 2005). A utilização desses reservatórios vem sendo associadas a outros tipos de usos, como lazer; melhorias da qualidade da água e, no caso de Goiânia associado à criação de parques, que atraem rapidamente o setor imobiliário.

Situada na porção sudeste do município de Goiânia a região de drenagem do córrego Cascavel, teve crescimento urbano estimulado diretamente por alterações nos padrões urbanísticos e de adensamento proposto pela Lei n' 171/2007. Tal situação induziu a seleção da área para pesquisas que avaliem os efeitos e impactos da impermeabilização nos canais de drenagem. O objetivo, portanto, desse estudo foi o de avaliar e prognosticar os impactos ambientais na região do alto curso do Córrego Cascavel (Figura 1) entre 2002 e 2012, considerando as intervenções de requalificação ambiental e reurbanização aplicadas à região.

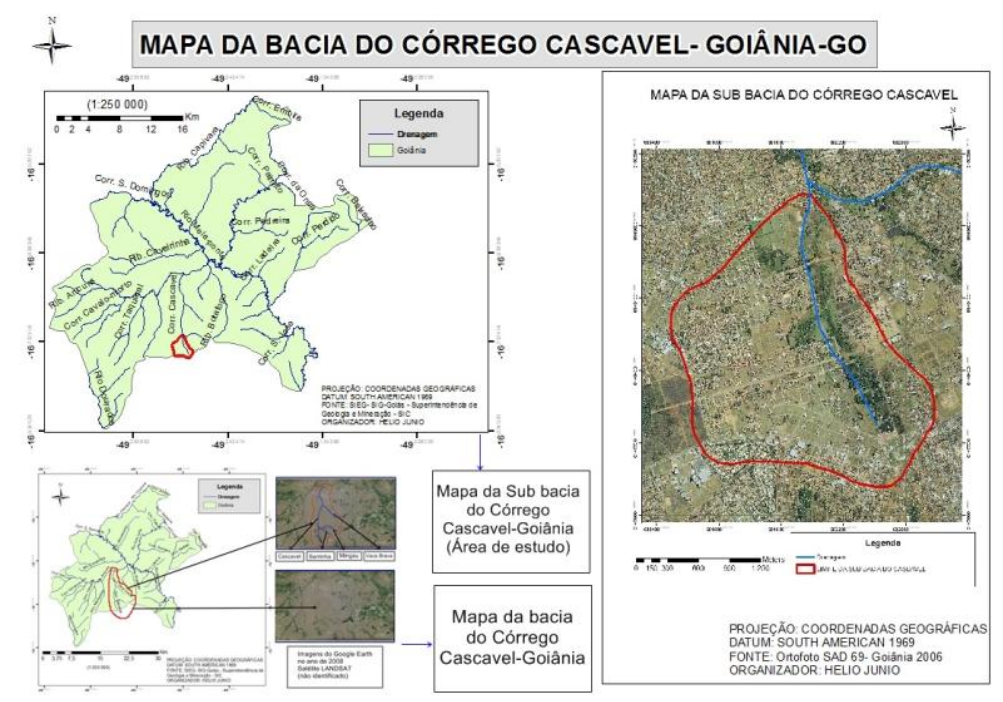

Figura 1- Mapa da localização da sub bacia do córrego Cascavel.

\section{Metodologia}

Os procedimentos operacionais envolveram além da usual revisão bibliográfica a classificação de imagens do CVES/Astrium, disponíveis no banco de dados do Google Earth; validação de dados em campo e análise integrada. A fim de avaliar as transformações urbanas e impactos ambientais adotaram-se 
como recorte temporal os anos de 2002 (anterior à requalificação) e 2012 (novo modelo de ocupação e após as intervenções).

O processo de classificação foi realizado com apoio de softwares de Sistema de Informação Geográfica (SIG) com identificação das classes: Impermeabilizadas: corresponde-se as áreas onde não há solo exposto e ou vegetação, como arruamentos e edificações; Permeáveis: são as áreas que possuem solo exposto e ou vegetação, correspondentes a loteamentos sem edificações, hortaliças, quintais não cimentados e áreas coberta por gramas; Vegetação: são as áreas de parques e APPs.

\section{Resultados e Discussões}

A UC Parque Cascavel passou durante o ano de 2006 por um processo de revitalização ambiental associado com projeto de reurbanização da região. O processo de revitalização ambiental envolveu a recuperação das áreas degradadas por processos erosivos fluviais acelerados, ausência de vegetação nativa, extração de solo (área de empréstimo), depósito de resíduos sólidos de origens diversas e disciplinamento de galerias de águas pluviais dentro da área delimitada como UC. O processo de reurbanização envolveu a pavimentação dos arruamentos e processo de verticalização de moradias e o procedimento de represamento para construção de lagos e considerando determinações do próprio plano diretor em estimular a adoção de medidas de drenagem sustentável.

Predominantemente as áreas verdes no município de Goiânia, quando transformadas em parques são extremamente visadas pelo setor imobiliário para grandes empreendimentos habitacionais, que "vendem" a imagem dos parques associadas aos imóveis. Trata-se de uma estratégia de marketing usada pelas grandes construtoras de levar ao comprador uma percepção de natureza, diante do conhecimento de que o futuro morador busca por uma imagem agradável e capaz de lhe proporcionar qualidade de vida (MIRANDA, 2014).

O parque Cascavel foi inaugurado em 2009 e atraiu logo no primeiro ano vários empreendimentos residenciais verticais para o entorno, que são co-responsáveis por ações antrópicas geradoras de impactos ambientais: a impermeabilização. Essa atividade é responsável pelo aumento dos escoamentos superficiais que demandam eficiência nos sistemas de macro e micro drenagem urbana.

O mapeamento evolutivo realizado (Figura 2) constata-se que houve aumento de 15,6\% das áreas impermeabilizadas; redução de 7,7\% das áreas permeáveis com o objetivo de melhoramento paisagístico para as construções verticais que se instalaram próximas ao parque Cascavel. 
XVII Simpósio Brasileiro de Geografia Fisica Aplicada

I Congresso Nacional de Geografia Física
OS DESAFIOS DA GEOGRAFIA FÍSICA NA FRONTEIRA DO CONHECIMENTO

Instituto de Geociências - Unicamp

Campinas - SP

28 de Junho à 02 de Julho de 2017

MAPA DE USO DO SOLO NO ALTO CURSO DA BACIA DO CÓRREGO CASCAVEL

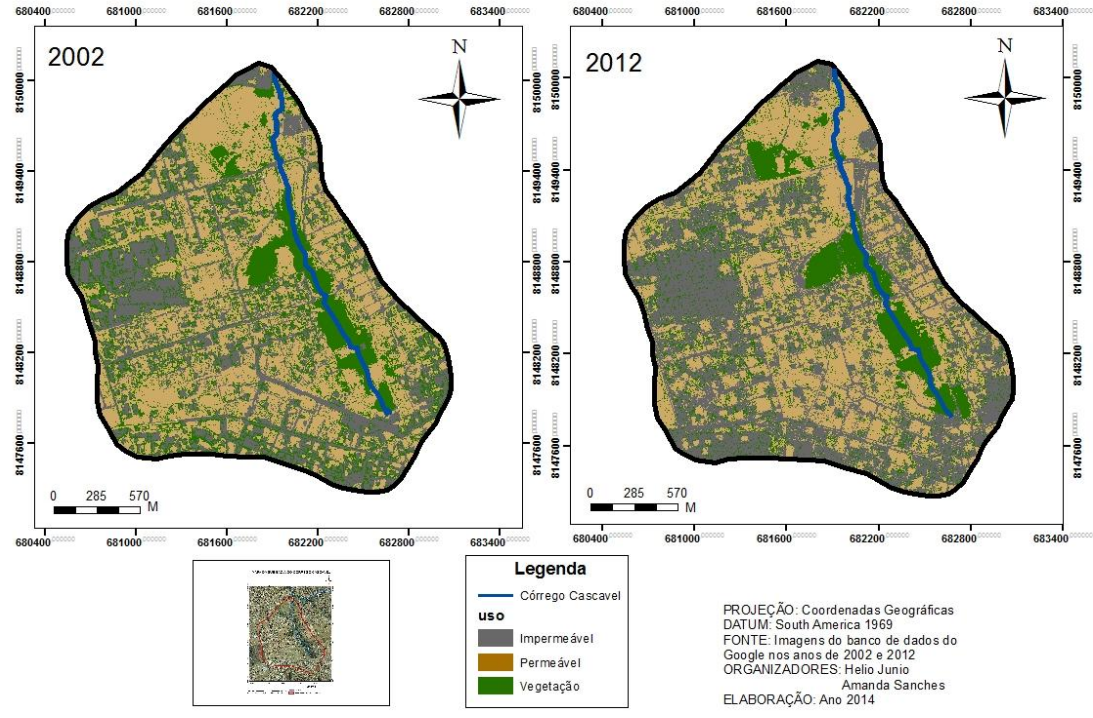

Figura 2 - Uso do solo no alto do Córrego Cascavel nos anos 2002 e 2012.

O aumento da impermeabilização e a redução das áreas permeáveis e da vegetação (redução de 7,9 $\%$ ), acrescidos de falhas no planejamento como a ausência de galerias pluviais, promovem na região o impacto de escoamento superficial concentrado. Esse impacto tem contribuído negativamente para o parque Cascavel, pois acarreta no aumento de erosões no parque, ocorrência de inundações e alagamentos na região. Mesmo com a recomposição provenientes de revegetações realizadas no Parque Cascavel, houve desmatamento de vegetação em lotes e arruamentos que foram incorporados à reurbanização.

A alteração das características morfológicas do solo em áreas urbanas é definitiva: o solo e o subsolo ficam expostos entre o início até o final da ocupação do loteamento e a produção de sedimentos tende a crescer. Os sedimentos depositados nas macrodrenagem reduzem a capacidade de escoamento de cheias dos canais e as inundações tornam-se mais frequentes (TUCCI; COLLISSCHONN, 1998).

E, tais fatos são observados e constatados na área de estudo. Com a visita a campo, pode-se constatar que nos últimos anos o poder público tem se ausentado nas manutenções do parque e nas áreas próximas a ele, considerando também as falhas de planejamento na construção do parque, sobretudo no que diz respeito ao disciplinamento das águas pluviais. O lago construído com a função de reservatório de detenção dos lançamentos existentes na área do parque encontra se assoreado e com um volume de água muito baixo, onde atualmente exerce a função de retenção de sedimentos, pois os sedimentos carreados dos processos erosivos estão depositados na área do lago.

Em pesquisa similar Ono, et al., (2005), constatou na bacia do Bananal, situada na Zona Norte da cidade de São Paulo, que o excesso do escoamento superficial, a degradação do solo, a poluição da água e 
as falhas nas obras de saneamento básico eram responsáveis pelos problemas de inundações e alagamentos registrados naquela bacia. Os pesquisadores reafirmaram que é uma demanda dos ambientes urbanos que algumas medidas de controle de escoamento sejam aplicadas para minimizar impactos. No caso do Parque Cascavel, estas medidas caracterizam se a princípio na necessidade do controle do escoamento superficial para dentro do córrego, e que, por conseguinte evitaria o surgimento de erosões e de alagamentos e inundações.

Entretanto, como constatado em campo e em consulta ao órgão ambiental a ação do poder público municipal, tomada apenas em 2015, reflete ainda medidas estruturais na atual rede de drenagem e limpeza do lago. Com o decorrer do tempo as medidas de contenção das erosões, alagamentos, inundações e escoamento superficial concentrado, irão se tornar mais difíceis de serem aplicadas.

\section{Considerações finais}

Os projetos de reurbanização no alto curso da bacia do córrego Cascavel contrastam com os efeitos da impermeabilização que resultou em aumento na frequência de alagamentos, inundações e erosões. Estruturas de drenagem urbana inovadoras, como bacias de retenção acabam sendo comprometidas devido aos sedimentos depositados nele, ocasionando na diminuição da capacidade de infiltração do solo, e na capacidade de amortecimento pluvial.

Embora haja grande especulação imobiliária na região, que ocasionou no aumento da impermeabilização do local, provocando um adensamento populacional, o poder público e o privado tem se omitido nas medidas de controle dos impactos identificados no parque Cascavel, permitindo que estes impactos se agravem mais, afetando então diretamente a qualidade de vida da população que habita a região.

\section{Referências}

CANHOLI, A. P. Drenagem urbana e controle de enchentes. São Paulo: Oficina de textos, 2005. GOIÂNIA. Câmera municipal de Goiânia. Plano diretor de Goiânia, 2008.

ONO, S.; BARROS, M. T. L. de.; CONRADO, G. A Utilização de SIG no Planejamento e Gestão de Bacias Urbanas. In: XVI Simpósio Brasileiro de Recursos Hídricos, 2005, João Pessoa - PB. Integrando a gestão da água às políticas sociais e de desenvolvimento econômico, 2005. v. 1. p. 471.

TUCCI, C. E. M; COLLISCHONN, W. Drenagem urbana e Controle de Erosão. VI Simpósio nacional de controle da erosão. Presidente Prudente-São Paulo, 1998. 